\title{
Exploration on Promoting the Teaching Effect of Construction Course in the Higher Vocational Architectural Education
}

\author{
Zhi Tang $\mathrm{Wu}^{1, \mathrm{a}^{*}}$ \\ ${ }^{1}$ Wenzhou Vocational \& Technical College, 325035, China \\ awzt1987000@163.com
}

Keywords: Construction course; Architectural education; Physical model; Teaching reform.

\begin{abstract}
In the light of some disadvantages in the past architectural construction teaching mode, the reformation should be put forward to this course and the specific measures ought to be the next. In this study, it is aimed to enable the students to understand two-dimensional plane drawings by the way of analyzing the three-dimensional entity architecture model for improving their space imagination before studying construction drawings, and finally, the students will draw the common detail of construction. Fortunately, the physical models were made for classes, which can be present and regrouped by them. Furthermore, it will cement the class in their mind by means of doing the construction experiment with the material in the classroom. Moreover, the related video was found and played for construction knowledge. This exploration was done to make the course easy to understand and improve the teaching effect.
\end{abstract}

\section{Introduction}

Architecture construction is an important professional fundamental course in architectural education. In Higher Vocational Education, it is the essential course for the architectural students who need to be trained mainly for their own expertise. The immediate duty of this course is developing their professional competence of reading and drawing the architectural construction plans. More specifically, construction course mainly introduces the common components of different buildings. As it should be, the principle and procedure of the architectural construction is instructed individually. Besides, it is necessary to learn this course for whether the Higher Vocational Architectural Education or the professional qualification examination of national registered architect. So, it's particularly important for letting the students have a better understanding of architectural construction, and finally improving the teaching effect as the same time as getting rid of the shortcomings in customary instructional design.

\section{Defects in customary course}

The course of construction is a new type of architectural curriculum. Freshmen in college still be used to forced-feeding method of teaching in the middle school. They can't use a sort of spatial or tactile giftedness that is beyond what any teen-age youths is likely to have. Although after graduation from high school they had a certain foundation in written language and logical thinking ability. Together with less attention and interest in details they pay in their everyday life. Then, the freshmen have not adequate knowledge of the internal structure of architecture. It is the key point of the reform in higher vocational college architecture teaching that training the student's creative ability is set as the target and improving the ability is the creative ability base. It seems to them that it is no use trying to do any project if the students really don't know the basic structure of the buildings. Not to mention how they create a wide variety of buildings, or make architectural creations.

Students were interested in their lessons at the beginning of the class as found in the process of teaching. However, the enthusiasm was falling down alongside the lesson progressed. The change has 
accelerated since art students were really weak at natural science and spatial imagination. Another phenomenon also struck some college teachers: a few homework finished by the students who listened carefully in class was terrible. In other words, some students didn't comprehend the architectural construction after class. Why? It's not enough that simply hearing in a college classroom. The way to cognize and apperceive should be broadened on the premise of knowing what is the construction and how to connect. Besides, it is necessary to look for a significant way of promoting the operative ability and developing the innovative potential and scientific research ability of the students. So, the abstract 2D plane should be expressed to the three-dimensional objects in the practical teaching. And more straightforward to say, object lesson should be introduced to the construction course. The ultimate aim of combining theory with practice is improving the quality of teaching.

\section{Curriculum design}

The main contents of the curriculum are as follows. Above all, the reformed construction course takes improving the quality of teaching that is on the premise of identifying talents training scheme as their starting point. It is the key to improve the college education quality for improving the classroom teaching quality. Furthermore, the teaching mode is integrated with the characteristics of higher vocational students. To adapt to this, the traditional teaching mode that characterized by teachers being the core and classroom teaching being the main form is reformed. The classroom which produced for this course is fully employed. The object lesson can visualize the empty theory especially construction details. Last but not least, students' perception in the process of learning gets better. The traditional two-dimensional perception, such as multimedia teaching and case teaching, is turned into three-dimensional perception. On the other hand, students are more interested in this course thanks to the 2D drawings are explained into physical models. In short, correct application of multi-media teaching, give full play to the advantages of object teaching, can improve the teaching effect, promoting teaching reform.

At the beginning of the term, how to make a reasonable arrangement for the time allocation between theoretical teaching and 3D model demonstration is a dominant issue. The principle of construction cannot be accomplished at one stroke owing to the various course contents. Likewise, the theory teaching and solid model explanation should be weaved. Both of them should be arranged into each teaching unit in order to let the students know well about every chapters and sections.

And the arrangement of most teaching units is as follows. The first two classes are used to teach the basic construction theory for the sake of enabling students to feel the buildings. For instance, students can master the floor construction and know why it should make level below the waterproof layer. Students know the "what" in the first two classes. Of course mastering construction course is about more than just memory, it is about understanding. The third lesson is mainly used for observing and learning the physical model which will reinforce the good students' message on the one hand, yet help the poor students to comprehend the $2 \mathrm{D}$ constructional drawing on the other. After all, it is entirely wrong to pay attention only to the one side and forget the other. As the saying goes, make hay while the sun shines. The students are arranged back to their desks for drawing the corresponding details in the last lesson. At the same time, the students will recall the construction in physical model. The knowledge is spread in the way of "learning by drawing" and " drawing by learning". At a few suitable teaching units, the students can participate in the site construction organized in the classroom. Moreover, the understanding of architectural construction is strengthened combine with multi-media of three-dimensional animation.

At the end of the semester, the students will know well about the whole material and construction of the physical model. In general, the ultimate purpose of this course is enable students to draw various architectural details at last. Yet the students can strengthen the weak sections and chapters by observing the physical model. In short, the teaching mode is gradual and multi-channel (see Figure 1). 


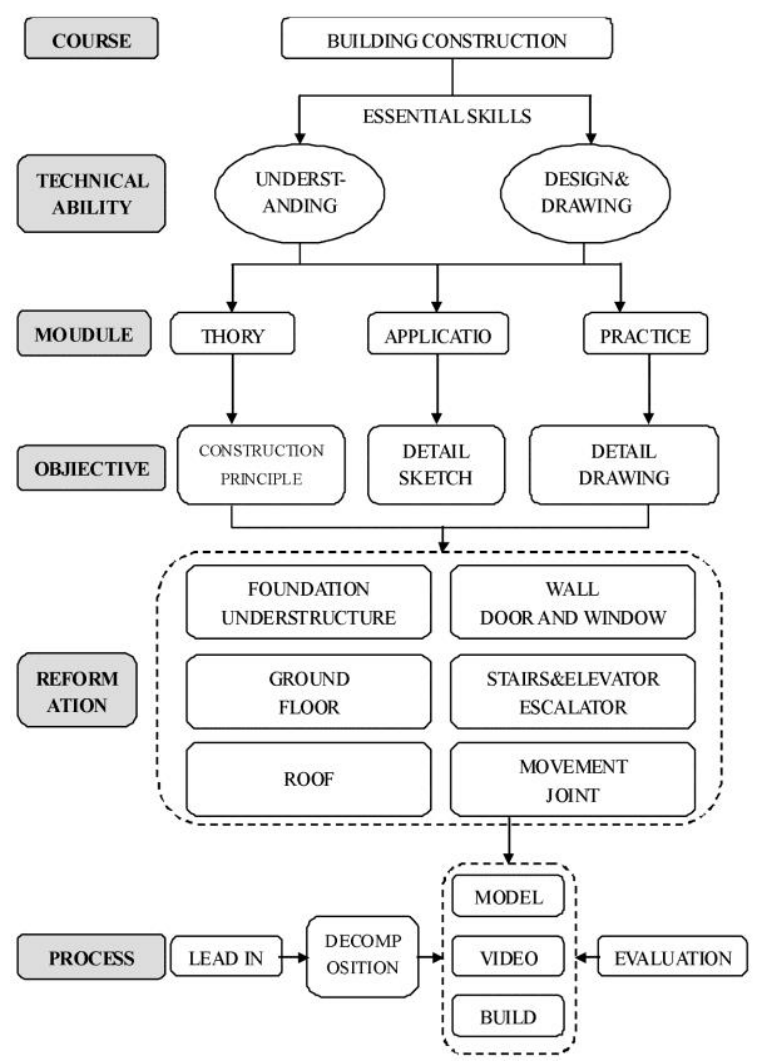

Figure. 1 Curriculum framework

\section{Teaching combined with physical model}

Establish the concept of space. The staff in building design institute can understand the usual detail drawings easily even draw them quickly by AutoCAD. Instead, it's more difficult to the college students for they are lack of practical engineering experience. In most cases, building construction drawings are two-dimensional. By contrast, we are actually living in three-dimensional environment just like all the objects are cube-like shapes. In the beginning, the students cannot understand 2D blueprint not to mention convert it to 3D objects in their minds. Therefore, teachers should show the explicit relationship between the plane drawing and architectural entity. Fortunately, the physical model which will be explained in the classroom can help the teachers and students. Here takes wall construction as an example. In all of wall construction layers, only decorative lamination can be watched in normal times. It's understandable that few students can imagine the specific materials and the relationship of them only by 2D blueprint. There are ways to reverse this. Specific steps are as follows. First of all, showing the 2D drawings and the corresponding $3 \mathrm{~d}$ objects (see Figure 2 ) to teach the basic principles of construction and answer student's questions. What matters is the anatomical model. The real purpose of the model is to take understanding to a new level. Then, they will draw the 2D drawings quickly from memory. As such, this may prove effective and deepen students' impression. The college students will not flit from story to story in the class. In other words, they can remember the drawings by seeing and understand the blueprint by doing. In the meantime, the fear of studying complicated construction will be removed. Some can make preparation for construction detail drawing which is the next mission. At the very least, this will establish the concept of space to the students also stimulate the student interest because of the intuitive guidance. 


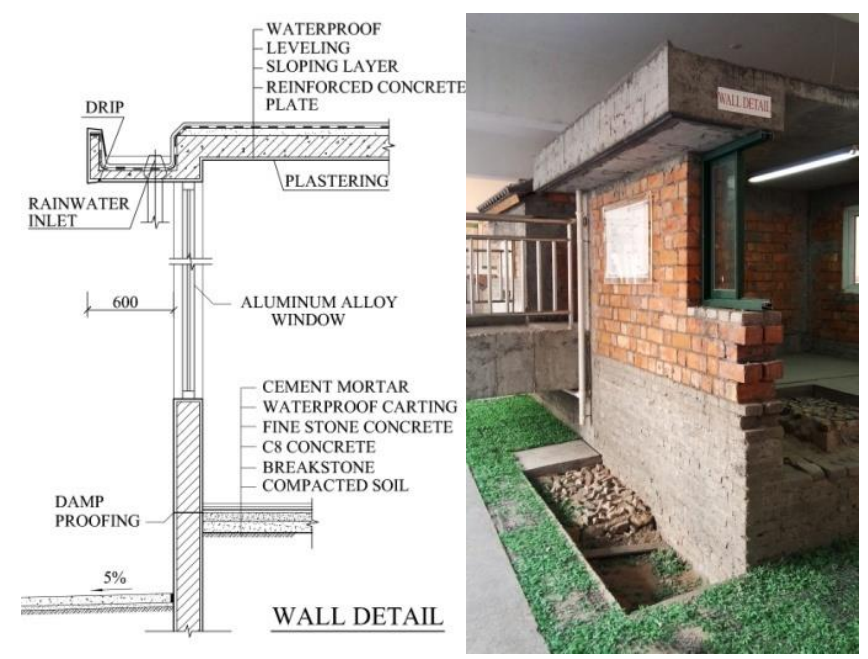

Figure. 2 Detail drawing and Physical model

Draw the usual detail drawings. It will never be enough for students only can image the space of ichnography. They should have the ability to drawing the usual detail drawings just for adapting to the job after graduation. It's a very practical skill. And it is not an issue if the students keep practicing the drawings according to the physical model. Soon afterwards the teacher will optimize and distribute the usual detail drawings to the class. Likewise, they will be order to draw the construction plan from memory after copy. Besides, the construction theory such as shelf life and construction control of the building materials should be enhanced, although the students have no access to such knowledge for they are arranged in the classroom. It is worth mentioning that teaching in the classroom avoids hidden danger in construction site. Eventually, the students will master most usual detail drawings as long as they practice unremittingly.

Teaching combined with operation. Two supplements should be proposed to deepen the architectural understanding after the students grasp the fundamental schematic diagram of construction. First is to insert constructional experiment such as pasting waterproof coiled material and laying bricks into the teaching platform. During the process of training applied talents, practice teaching is very important. The other one is to insert material experiment such as determination on the property of mortar and concrete into the teaching platform. Operations should be considered in teaching for some material and construction is vital. It's particularly helpful for embodying the 2D detail drawings.

Teaching combined with video. To a degree, the traditional slideshow can visualize architectural structure. The pictures and text are difficult to demonstrate not only complicated layers but also construction processes. Operation and physical models in the classroom showed limited material and construction that is not enough. Also, the whole construction period cannot be seen. The difficulties can be easily solved by teaching videos. The video is divided into two categories. The first type is about constructional composition which shows how each member connects and assembles. For instance, the video for escalator shows all details about how to piece together the motor, driving belts, bolts and steps. The videos which demonstrate the structures unseen in daily life are $3 \mathrm{D}$ animation. The other type is about constructional process which shows the procedure from foundation tamping to roof waterproof. The videos is achieved by sharing among the internet and teachers.

\section{Summary}

The construction course is combined with the operation, physical model and teaching video for exploring better teaching effect. The reform in this course has not only changed the traditional teaching mode which mainly used the slides but also stimulate the student interest that resulted in better teaching effect according to the students' classroom behavior and homework. The purpose of studying 
architectural construction lies in improving the design ability for college students. Further, we should continue to explore possible and effective means in the case of enabling them to create detail drawings and applying that in architectural creations.

\section{References}

[1] A.A. Wael: Sci. Computer Science, Vol. 25 (2013), p. 220-230.

[2] P.B.Z. Ozlem: Social and Behavior Science, Vol. 106 (2013), p.1636-1647.

[3] D. Serap and O.G. Sengul: Social and Behavior Science, Vol. 15 (2011), p.1586-1594.

[4] S.O. Gur: What is creative? Creativity in architectural theory, practice and education (Design Train Congress, Holland 2008).

[5] M.J. Abbolt: The Bauhaus and the Design Theory (Thames and Hudson, UK 1993).

[6] N. Oliveira and M.N. Petry: Installation Art (Thames and Hudson, UK 1997).

[7] S.A. Gruzdys: Architectural Record, Vol. 190(2002) No.1, p.64-67.

[8] Z. Ulusoy: Design Studies, Vol. 20(1999), p.123-130.

[9] Y. Yamamoto, K. Nakakoji and S. Takada: Knowledge-Based Systems, Vol. 13(2000), p.375-384.

[10] R. Arnheim: The Dynamics of Architectural Form.( University of California press, USA 1977)

[11] C.S. Nils and P. Jaccard: Governance and Performance of Education Systems (Springer-Verlag, Germany 2008). 